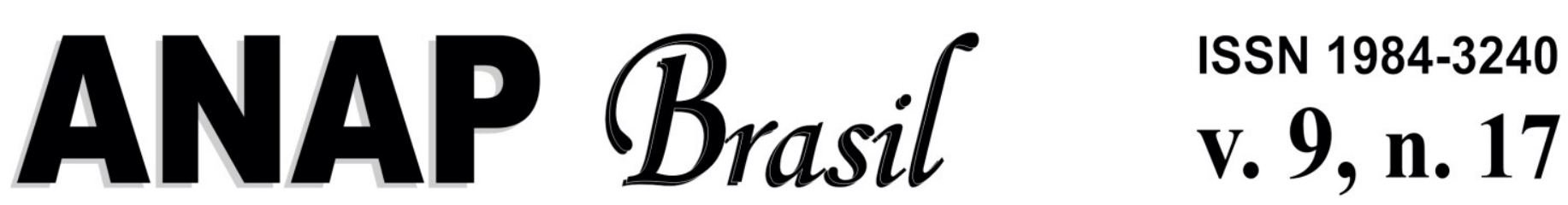

\title{
Investigação do Potencial de Contaminação Ambiental Associado à Disposição em Solo de Resíduos Asfálticos
}

Potential of Environmental Contamination Associated with Disposal of Asphalt Waste in Soil

Potencial de contaminación del medio ambiente asociados con la eliminación de residuos en el suelo de asfalto

André Nagalli Professor Doutor, UTFPR, Brasil nagalli@utfpr.edu.br

Emanuelle Dayane Schneider Mestrando em Eng. Civil, UTFPR, Brasil emanuelle.schneider@hotmail.com

Mariana Reinert Schroh Mestrando em Eng. Civil, UTFPR, Brasil mariana_schroh@hotmail.com 


\section{INTRODUÇÃO}

O Brasil é um país cujo transporte é predominantemente rodoviário, porém, segundo a CNT (Confederação Nacional do Transporte, CNT,2015), 80\% da malha rodoviária do país é não pavimentada. Com isso, há uma grande demanda de obras de pavimentação, tanto para novas rodovias quanto de manutenção, pois as rodovias já pavimentadas, que são minoria, ficam sobrecarregadas por oferecerem melhores condições de tráfego. Mesmo com o desenvolvimento de tecnologias com a finalidade de aumentar a durabilidade do pavimento, a geração desse tipo de resíduo ainda é alta, estima-se que só em Curitiba, são gerados 50 mil $\mathrm{m}^{3}$ ao ano (PREFEITURA MUNICIPAL DE CURITIBA, 2014).

O resíduo proveniente de substituição ou retirada de pavimentação asfáltica é considerado, pela Resolução CONAMA no 307/02 do Conselho Nacional do Meio Ambiente (CONAMA, 2002), como entulho da construção civil, devendo ser destinados para reciclagem ou reutilização na forma de agregado ou, quando não houver essa possibilidade, para aterros de resíduos da construção civil. Porém, a escassez de áreas de destinação final licenciadas e de empresas recicladoras autorizadas pelo poder público dentro do perímetro urbano, torna o descarte de desse tipo de resíduo dispendiosa e propicia a ilegalidade. A disposição inadequada de resíduos ocasiona impactos ambientais, que vão além do comprometimento do solo e corpos de água, culminando em proliferação de vetores de importância sanitária, além de catação em condições insalubres na região da disposição (BESEN et al., 2010)

Usualmente, entulhos da construção civil são classificados, por exceção, como de Classe IIB, conforme a ABNT NBR 10.004:2004 (ASSOCIAÇÃO BRASILEIRA DE NORMAS TÉCNICAS, 2004a), por serem considerados inertes (JOHN; AGOPYAN, 2000). Segundo Butera et al. (2014), para classificar um resíduo como inerte, leva-se em consideração apenas suas propriedades inorgânicas, havendo poucos estudos que identifiquem seus componentes orgânicos.

Os asfaltos são misturas complexas com considerável variedade de compostos orgânicos (Binet et al., 2002), dentre eles, os hidrocarbonetos policíclicos aromáticos (HPAs). Os HPAs são estruturas constituídas de dois ou mais anéis benzênicos, gerados pela queima incompleta de combustíveis fósseis, processos diagenéticos de formação de combustíveis fósseis, na exaustão de motores a gasolina, na combustão do diesel e em outros processos de combustão parcial no qual o carbono 20 ou combustível não são convertidos em monóxido ou dióxido de carbono. Estes compostos são dificilmente degradáveis e tendem a se acumular nos mais diversos setores ambientais, devido a suas propriedades físico-químicas (COTTA et al., 2009).

Estudos em matrizes ambientais, como derivados da combustão de carvão, exaustão dos veículos, óleos lubrificantes, fumaça do cigarro, dentre outros, têm demonstrado que os HPAs presentes nestas misturas são os principais responsáveis pelo seu potencial de toxicidade (Campo et al., 2006). Vários trabalhos têm relatado efeitos adversos produzidos pelos HPAs, 


\section{ANAP

principalmente os relacionados ao desenvolvimento de câncer. Por esse motivo a United States Environmental Protection Agency (USEPA) incluiu 16 tipos de HPAs em sua lista de poluentes prioritários, e tem desenvolvido métodos para monitoramento dessas substâncias no ambiente (COTTA et al., 2009). Butera et al. (2014) realizaram ensaios em amostras de RCDs de aterros dinamarqueses a fim de determinar teores de HPA e de bifenil policlorado (BCP), através de extração por micro-ondas assistidas e análises por cromatografia líquida de alta eficiência (CLAE), e concluíram que em todas as amostras contendo resíduo asfáltico, as proporções de HPA ficaram acima do permitido pela legislação local.

Neste trabalho foram adaptados métodos para avaliar a presença de Hidrocarbonetos Policíclicos Aromáticos - HPAs - em duas amostras de resíduo asfáltico: uma retirada da região do bairro Pinheirinho, na cidade de Curitiba e outra proveniente da avenida Portuária em Paranaguá.

\section{OBJETIVOS}

O objetivo deste trabalho é a detecção de Hidrocarbonetos Policíclicos Aromáticos (HPAs) em amostras de resíduos asfáltico coletadas nas cidades e Curitiba/PR e Paranaguá/PR. Para esse estudo foram selecionados os 16 tipos de HPAs na lista de poluentes prioritários da USEPA.

\section{METODOLOGIA}

A figura 1 apresenta a sequência de procedimentos realizados para execução deste trabalho. 


\section{ANAP $\mathfrak{B r a s i l}$

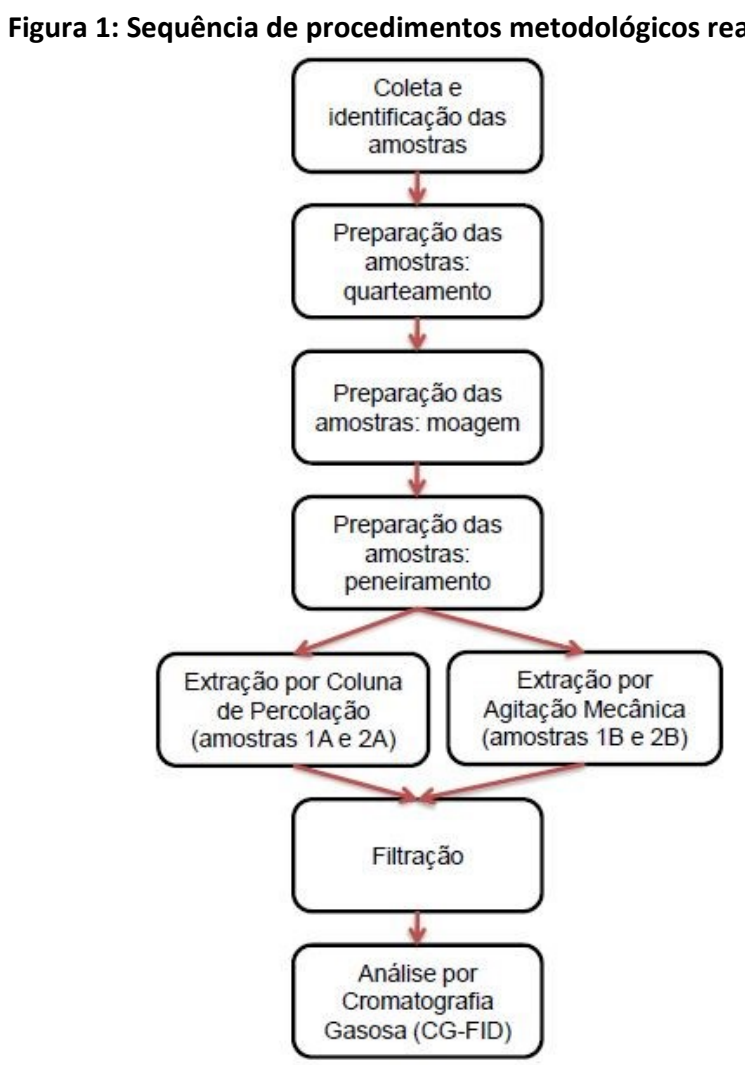

Fonte: AUTORIA PRÓPRIA, 2015.

Foram coletadas amostras da cidade de Paranaguá e da cidade de Curitiba, destacadas nesse estudo como Amostra 1 e Amostra 2, respectivamente. A Amostra 1 correspondeu ao resíduo asfáltico decapado, proveniente do recapeamento da Avenida Portuária, no bairro Dom Pedro Il em Paranaguá. O traço utilizado na sua confecção foi de $80 \%$ de pó e pedrisco, $14 \%$ de brita 1 e 6\% de Cimento Asfáltico de Petróleo (CAP). A Amostra 2 dispôs de resíduo asfáltico fresado, derivado do trecho recapado no ano de 2014, situado na Rua André Ferreira Barbosa, no bairro do Pinheirinho e com traço de mesma composição descrita anteriormente. Foram coletados em torno de $30 \mathrm{~kg}$ de cada amostra.

Primeiramente foram feitos os recebimentos e inspeções da amostras coletadas para a retirada de material orgânico, vidros e plásticos. Para realização do quarteamento, utilizou-se como referência o método descrito pela ABNT NBR 10.007/2004 (ASSOCIAÇÃO..., 2004b). O quarteamento foi feito manualmente. O resíduo foi distribuído sobre o piso revestido com lona plástica, para evitar perda de material ou possível contaminação da amostra por outros resíduos. Na sequência, o material foi revolvido com auxílio de pás para obter sua homogeneização completa e foi formada uma pilha em formato cônico. O cone foi rebatido na superfície e dividido em quatro partes iguais, seguido da remoção de dois quartos opostos de material (em sentido diagonal). Os outros dois quartos opostos de material remanescentes 
foram reunidos e um novo quarteamento foi realizado da mesma forma. Essa operação foi repetida mais duas vezes até obter a quantidade de amostra necessária para os ensaios, de aproximadamente $3 \mathrm{~kg}$. Esse procedimento foi igualmente executado para as duas amostras. Após quarteadas, as amostras foram dispostas em bandejas metálicas, com identificação, e levadas à estufa em temperatura de $50 \stackrel{\circ}{C}$ por $72 \mathrm{~h}$ para secagem. Devido as características físicas (tamanho de grãos) da Amostra 1, foi necessária moagem do resíduo asfáltico, sendo utilizado neste trabalho o Moinho de Bolas Solotest. Também houve a necessidade de peneiramento das amostras para seleção de grãos passantes pela $2,4 \mathrm{~mm}$, como base desse procedimento, utilizou-se a ABNT NBR NM 248:2003 (ASSOCIAÇÃO..., 2003).

A extração foi realizada por meio de dissolução em líquido, procedimento denominado lixiviação. Como a água é o principal agente do intemperismo, as técnicas empregadas visaram a simulação da degradação do material devido à ação da natureza. Para acelerar o procedimento, foi utilizado, como agente extrator, mistura entre água ultrapura obtida do equipamento Mega Purity Water Purification System e etanol a $20 \%$.

As técnicas empregadas para extração do analito foram por coluna de percolação, FIGURA 2, e agitação mecânica, FIGURA 3.

No Quadro 1 estão indicadas as denominações utilizadas para as amostras de acordo com o procedimento de extração.

Quadro 1: Denominação das amostras de acordo com o procedimento de extração

\begin{tabular}{ccc}
\hline Amostra & Denominação & Procedimento de Extração \\
\hline Amostra 1 & $1 \mathrm{CP}$ & Amostra 1 - Extração por Coluna de Percolação \\
Amostra 2 & 1AM & Amostra 1 - Extração por Agitação Mecânica \\
& $2 \mathrm{CP}$ & Amostra 2 - Extração por Coluna de Percolação \\
& $2 \mathrm{AM}$ & Amostra 2 - Extração por Agitação Mecânica \\
\hline
\end{tabular}

FONTE: AUTORIA PRÓPRIA, 2015.

No ensaio por coluna de percolação, a coluna foi preenchida com amostra a ser analisada e empacotada de forma a minimizar os vazios e assegurar resistência à passagem do liquido extrator através da coluna. O empacotamento da amostra na coluna foi realizado manualmente com impactos intensos externos à coluna com auxilio de béquer plástico para em toda extensão da coluna. $O$ empacotamento foi feito pela primeira vez para atestar 0 volume necessário para a realização do ensaio. A amostra foi retirada da coluna, pesada, para definir a relação entre amostra e líquido extrator, e reempacotada. $O$ conjunto foi posicionado verticalmente na haste metálica de apoio e conectada com Erlenmeyer de $2 \mathrm{~L}$ de capacidade superior e inferior através das mangueiras de silicone. O líquido extrator foi depositado no 


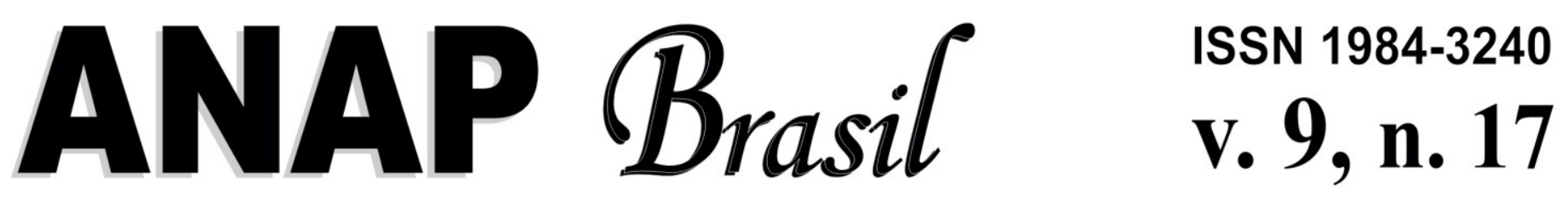

\section{REVISTA CIENTÍFICA}

Erlenmeyer superior, de forma a iniciar o fluxo através da coluna, e recirculado repetidamente por 5 dias.

No ensaio por agitação mecânica, a amostra foi inserida no balão volumétrico com capacidade de $500 \mathrm{ml}$, com etanol $20 \%$ nas seguintes quantidades: $425 \mathrm{ml}$ de líquido extrator e $50 \mathrm{~g}$ de resíduo asfáltico da amostra $1 \mathrm{AM}$ e $500 \mathrm{ml}$ de líquido extrator e $63 \mathrm{~g}$ de resíduo asfáltico para a amostra 2AM. O balão foi acoplado ao motor com rotação de 40 rpm durante 5 dias.

Os lixiviados obtidos, por ambos os métodos, foram filtrados e transferidos para garrafas âmbar identificadas e acondicionadas em caixas térmicas com gelo para manter as características e assegurar a confiabilidade dos resultados das análises das amostras de resíduos asfálticos.

Figura 2 - Coluna de Percolação: 1 Erlenmeyer superior; 2 - coluna de percolação; 3 - Erlenmeyer inferior; 4 - mangueiras de silicone.

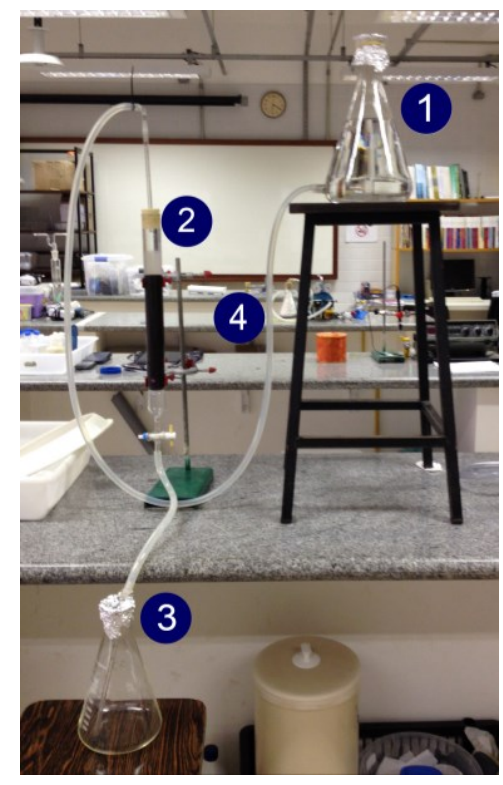

Fonte: AUTORIA PRÓPRIA, 2015.
Figura 3 - Agitação mecânica: 1 - dispositivo de controle de rotação; 2 - balão volumétrico contendo amostra e líquido extrator.

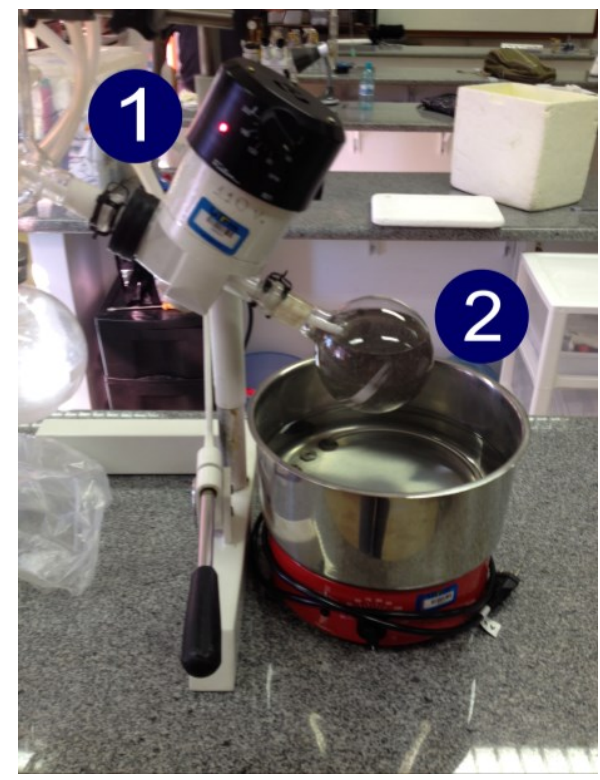

Fonte: AUTORIA PRÓPRIA, 2015.

As amostras foram encaminhadas ao laboratório para análise por cromatografia gasosa. Foi utilizado cromatógrafo gasoso da marca Hewllet Packard (HP), modelo 5890 Série II, com injetor Splitless/Normal. A coluna foi a Capilar - VF - 5ms Agilent Technologies, com $30 \mathrm{~m}$ de comprimento, 0,25 mm de diâmetro interno e 0,25 $\mu \mathrm{m}$ de espessura do filme. $O$ injetor operou no modo splitless com temperatura de 200 ํ. A. A separação foi realizada com programação de temperatura do forno, sendo a temperatura inicial de 35 o $C$ mantida isotérmica por 2 minutos, seguida de aumento linear até 95 ㅇ (12 을 durante 5 minutos)

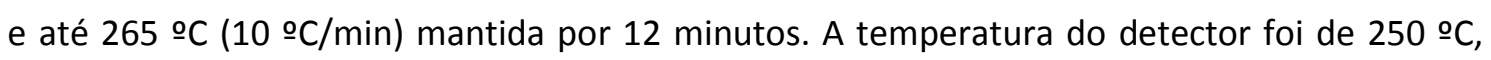
operado com uma chama de Hidrogênio com vazão de 15 a $25 \mathrm{~mL} / \mathrm{min}$ e o gás de arraste utilizado foi o Nitrogênio, com vazão de 6 a $8 \mathrm{~mL} / \mathrm{min}$. O padrão utilizado foi o PAH Mix, obtido 
da empresa Accustandard, em conjunto com o solvente diclorometano. Foram necessários cerca de 14 dias para a emissão dos laudos das análises de cada amostra.

\section{RESULTADOS}

Foram detectados HPAs em todas as amostras de resíduos asfálticos analisadas. Na Tabela 1 são apresentados os resultados experimentais para os teores de HPAs obtidos nos lixiviados de resíduos asfálticos após análise por cromatografia gasosa (CG). Também estão expostos os valores encontrados por Butera et al. (2014) e os valores limites permitidos para solos pela Resolução CONAMA no 460/13. Os demais HPAs não mencionados na Tabela 1, tiveram seus valores abaixo do limite de detecção do equipamento cromatográfico.

Tabela 1 - Resultados obtidos para as amostras após a análise por CG, valores encontrados por Butera et al. (2014) e valores limites do CONAMA para as amostras 1CP (amostra 1 por coluna de percolação), 1AM (amostra 1 por agitação mecânica), 2CP (amostra 2 por coluna de percolação) e 2AM (amostra 2 por agitação mecânica).

\begin{tabular}{ccccccc}
\hline \multirow{2}{*}{ HPAs } & \multicolumn{3}{c}{ AMOSTRAS $\mathbf{( m g / k g )}$} & $\begin{array}{c}\text { Butera et al. (2014) } \\
\text { (mg/kg) }\end{array}$ & $\begin{array}{c}\text { CONAMA 460:2013 } \\
\text { Solos (mg/kg) }\end{array}$ \\
\cline { 2 - 5 } & $\mathbf{1 C P}$ & $\mathbf{1 A M}$ & $\mathbf{2 C P}$ & $\mathbf{2 A M}$ & 0,8000 & Não mencionado \\
\hline Acenaftileno & 0,0027 & 0,1998 & 0,1411 & 0,3454 & 0,1000 & 0,0390 \\
Antraceno & 0,0621 & 0,0036 & 0,0117 & 0,1910 & 3,3000 \\
Fenantreno & 0,0619 & 0,0036 & 0,0119 & 0,1910 & 2,4000 & Não mencionado \\
Fluoranteno & 0,0471 & $<0,02$ & $<0,02$ & $<0,02$ & 20 & Não mencionado \\
Fluoreno & 0,1739 & 0,2734 & $<0,06$ & $<0,06$ & 0,33 & 0,1200 \\
Naftaleno & 0,0081 & 0,1780 & 0,0933 & 0,0729 & 0,1600 & 0 \\
\hline
\end{tabular}

Fonte: Adaptado: BUTERA et al. (2014), CONAMA 460/13, CASTRO (2010) E AUTORIA PRÓPRIA, 2015.

Os limites de concentração definidos na Resolução CONAMA no 460/13, sumariamente apresentados na Tabela 9, definem valores orientadores de qualidade no solo, enquanto os valores obtidos após as análises cromatográficas das amostras $1 \mathrm{CP}, 1 \mathrm{AM}, 2 \mathrm{CP}$ e $2 \mathrm{AM}$, indicam as concentrações na matriz sólida. No entanto, vale ressaltar que o antraceno, para as amostras $1 \mathrm{CP}, 2 \mathrm{CP}$ e $2 \mathrm{AM}$, e o naftaleno para a amostra $1 \mathrm{AM}$, foram detectados acima dos limites de concentrações estabelecidas pelo CONAMA no 460/13 e, portanto, podem ser agente potencial contaminante do solo.

Entre os HPAs detectados, o fluoranteno, encontrado na amostra $1 \mathrm{CP}$, e o naftaleno, encontrado em todas as amostras, conferem periculosidade ao resíduo, segundo descrito na ABNT NBR 10.004:2004 (ASSOCIAÇÃO..., 2004a).

A utilização do etanol a $20 \%$ como líquido extrator teve como objetivo de aumentar a solubilidade dos compostos na matriz líquida, sendo possível observar que os componentes detectados nas amostras analisadas são os mais solúveis em água. Assim, a não detecção dos 
demais HPAs não significa, necessariamente, sua ausência nas amostras, pois como os analitos foram extraídos por lixiviação, a baixíssima solubilidade de alguns compostos dificulta sua detecção.

Em relação às concentrações, embora os valores de concentração sejam bastante diferentes, há concordância com relação à presença das substâncias, o que indica a não inocuidade ambiental das amostras. Além disso, não foi detectada padronização nas quantidades de concentrações, não sendo possível indicar um dos métodos como mais eficiente.

Os resultados obtidos por Butera et al. (2014) apresentaram concentrações superiores aos encontrados para as amostras $1 \mathrm{CP}, 1 \mathrm{AM}, 2 \mathrm{CP}$ e $2 \mathrm{AM}$. Essa discrepância pode ser devida ao fato de que os autores utilizaram método de micro-ondas assistidas para extração dos analitos, que garante baixo consumo de solventes, alta eficiência de extração e reduzido tempo de análise (PINO et al., 2000) em comparação com os métodos utilizados nesse trabalho. Além disso, os autores não especificam a composição dos resíduos asfálticos analisados, o que dificulta a comparação, considerando a variabilidade dos materiais que compõem os resíduos asfálticos.

\section{CONCLUSÃo}

Os métodos desenvolvidos para extração de HPAs de resíduos asfálticos por lixiviação, com utilização de coluna de percolação e agitação mecânica, se mostraram eficientes, tendo em vista que, combinado com a análise por cromatografia gasosa, foi possível a detecção das substâncias procuradas.

A detecção dos HPAs nas amostras de resíduo asfáltico suscita um alerta em relação à orientação de destinação desse material. O naftaleno foi identificado em todas as amostras e sua presença deve ser destacada, pois esse componente é citado na NBR 10004:2004 como substância que confere periculosidade aos resíduos sólidos.

Esse estudo mostrou a presença de HPAs nas amostras de resíduos asfálticos analisadas, o que sugere um potencial de contaminação do ambiente, abrindo espaço para investigações mais aprofundadas em relação à quantificação dessas substâncias nesse tipo de resíduo, bem como sua correta disposição, e os efeitos nocivos para o solo, água e seres vivos.

\section{REFERÊNCIAS BIBLIOGRÁFICAS}

CONFEDERAÇÃO NACIONAL DO TRANSPORTE-CNT. Boletim Estatístico, julho de 2015. Disponível em: < www.cnt.org.br/Paginas/Boletins_Detalhes.aspx?b=3 >. Acesso em 27 out. 2015

ASSOCIAÇÃO BRASILEIRA DE NORMAS TÉCNICAS. NBR 10.004: Resíduos sólidos - Classificação. Rio de Janeiro, 2004a.

. NBR 10.007:Amostragem de resíduos sólidos. Rio de Janeiro, 2004b. 
. NBR NM 248:Agregados - Determinação da composição granulométrica. Rio de Janeiro, 2003.

BESEN, Gina R. Resíduos sólidos: vulnerabilidades e perspectivas. In: SALDIVA P. et al. Meio ambiente e saúde: o desafio das metrópoles. São Paulo: Ex Libris, 2010.

BINET, S.; PFOHL-LESZKOWICZ. A.; BRANDT. H.; LAFONTAINE M.; CASTEGNARO M. Bitumen Fumes: Review of Work on the Potential Risk to Workers and the Present Knowledge on its Origin. The Science of the Total Environment. United States of America. 2000.2 Disponível <https://comitatosavignano.files.wordpress.com/2009/05/sciencetotalenv300-2002-binet-bitumenfumesrisk.pdf>. Acesso em: 30 jan. 2015.

BRASIL. MINISTÉRIO DO MEIO AMBIENTE, CONSELHO NACIONAL DO MEIO AMBIENTE - CONAMA. Resolução no. 307, de 05 de julho de 2002. Brasília DF, n. 136, 2002.

. Resolução no 460, de 30 de dezembro de 2013. Brasília DF, n. 249, 2013.

$\overline{B U T E R A}$, Stefania; CHRISTENSEN, Thomas. H.; ASTRUP, Thomas.F. Composition and leaching of construction and demolition waste: inorganic elements and organic compounds. Journal of Hazardous Materials, 2014.

CAMPO, Laura; ADDARIO, Liliana; BURATTI, Marina; SCIBETTA, Licia; LONGHI, Omar; VALLA, Carla; CIRLA, Piero E.; MARTINOTTI, Irene; FOÀ, Vito.; FUSTINONI, Silvia. Biological monitoring of exposure to polycyclic aromatic hydrocarbons by determination of unmetabolized compounds in urine. Toxicology Letters, v. 162. 2006.

CASTRO, Danielle B. de. Estudo em modelo físico 1D e 3D de remediação eletrotécnica com uso de tensoativo em solo argiloso contaminado com óleo cru. 2010. 132 f. Dissertação (Mestrado em Engenharia Civil) - Universidade Federal do Rio de Janeiro, Rio de Janeiro, 2010.

COTTA, Jussara A. O.; RESENDE, Maria O. O., LANDGRAF, Maria D. Avaliação de solventes de extração por ultrassom usando-se cromatografia líquida de alta eficiência para a determinação de hidrocarbonetos policíclicos aromáticos em solos contaminados. Química Nova, São Paulo, v. 32, n. 8, out. 2009. Disponível em: <http://www.scielo.br/pdf/qn/v32n8/v32n8a09.pdf>. Acesso em: 03 ago. 2014.

JOHN, Vanderley M.; AGOPYAN, Reciclagem de resíduos da construção. Seminário de Resíduos Sólidos, 1.,2000. Disponível em: <http://www.reciclagem.pcc.usp.br>. Acesso em: 24 ago. 2016.

PINO, V., AYALA, J.H, AFONSO, A.M, GONZALEZ, V. Determination of polyciclic aromatic hydrocarbons in marine sediments by high-performance liquid chromatography after microwave-assisted extraction with micelar media. Journal of Chromatography, 2000.

PREFEITURA MUNICIPAL DE CURITIBA. Prefeitura cadastra empresas para reciclagem de resíduos asfálticos. Agência de Notícias da Prefeitura de Curitiba, Curitiba, 16 jan. 2014. Disponível em: $<$ http://www.curitiba.pr.gov.br/noticias/prefeitura-cadastra-empresas-para-reciclagem-de-residuosasfalticos/31728>. Acesso em 17 mai. 2014. 